\title{
Status and Eradication of Polio in Pakistan
}

\author{
Savaira Jabbar ${ }^{1}$, Muhammad Rizwan Hamid $^{* 1,3}$, Hafiz Husnain Nawaz ${ }^{1 *}$, Sadia Zahid ${ }^{1}$, Muham- \\ mad Sajid ${ }^{2}$ and Su Pin ${ }^{3}$
}

${ }^{1}$ Department of Microbiology and Molecular Genetics, University of Okara, Pakistan

${ }^{2}$ Department of Biotechnology, University of Okara, Pakistan

${ }^{3}$ Key Laboratory of Pest Management of Horticultural Crops of Hunan Province, Hunan Academy of Agricultural Science, China

*Corresponding author: Muhammad Rizwan Hamid (rizwan.phyto@outlook.com)- Department of Microbiology and Molecular Genetics, University of Okara, Okara, Punjab, Pakistan, Key Laboratory of Pest Management of Horticultural Crops of Hunan Province, Hunan Plant Protection Institute, Hunan Academy of Agricultural Science, Changsha, China.

Hafiz Husnain Nawaz (h_husnain_012@yahoo.com), Department of Microbiology and Molecular Genetics, University of Okara, Okara, Punjab, Pakistan.

To Cite This Article: Savaira J, Muhammad Rizwan H, Hafiz Husnain N, Sadia Z, Muhammad S, Su Pin. Status and Eradication of Polio in Pakistan. 2020 - 9(5). AJBSR.MS.ID.001435. DOI: 10.34297/AJBSR.2020.09.001435.

Received: 眥February 12, 2020; Published: 漹 July 29, 2020

\begin{abstract}
Poliomyelitis is a highly endemic and fetal disease, which mainly act on children under five years of age initial to irreversible paralysis and possibly death. For decades, both private and government organizations have been putting trials through their partnership to eradicate polio entirely from the different parts of the globe and as a result of those trials are left with only three countries which are now polio endemic. Since Pakistan is one of those three countries which still remain polio endemic along with Nigeria and Afghanistan. Therefore, it is important to deal with this issue and work on the remedy to control the situations of such harmful disease.
\end{abstract}

Keywords: Poliomyelitis; Pakistan; Endemic; Eradication

\section{Introduction}

Poliomyelitis belongs to family Picornaviridae commonly abbreviated as "polio". It is one of the most scary viruses of the twentieth century in the world. It is considered as the opener of the global initiative program for the eradication of polio by WHO in 1988. Polio is a positive sense single stranded RNA enterovirus. It affects the gray matter of spinal cord, causes an irreversible acute flaccid paralysis (AFP) mostly in children under five because of affected motor neurons. It may cause death if respiratory muscles or throat get paralyzed, but fortunately that is not quite often [1]. There are three serotypes of polio virus, which affect the human cells specifically through PVR CD-155 receptors, although their virulence potential is different [2]. In this review, we are going to discuss the status and eradication of polio in Pakistan.

\section{History}

Firstly, the polio virus was defined by Michel Underwood in 1789. According to him, it is derived from the Greek word "polios" meaning "gray" and "myelos" meaning "spinal cord" [3]. Most of the work of different scientists published in the period from 1840-1949 including Paul Frosck, Jacob Hein, Adolf Strumpell, John Rissler, Oskar Medin, Lvar Wickman, Romer, Flexner, Lewis, Leiner, Vos Weisner, Landsteiner and Lavoditi. First time the natural history of human poliomyelitis was given by Albert Sabin and Robert Ward in 1912 [4].

\section{Epidemiological condition of polio in Pakistan}

The challenges of health system of Pakistan are aggregated by a crucial geography, from the north's Himalayan glaciers to 
the south's rough and tough area of Balochistan. This condition contributing poor public sector health delivery [5]. In 2014, a total of 306 cases of polio were recorded and diagnosed in Pakistan. Nearly $80 \%$ of all worldwide cases were accounted in that record. At that time, India was declared as polio free country [6]. About 53 new cases were reported in 2015 [7]. Nearly 96\% were reported from the Khyber Pakhtunkhwa province out of the total diagnosed cases in Pakistan. In 2016, on the Global Prosperity Index, Pakistan was ranked 132 out of 142 countries. On the Human Development Index, the status of Pakistan's human development had been very low over the consistent last 5 years ranked 147 [8].

It is crucial to analyze the articulacy rate and epidemiological conditions in the regions to understand the ascendancy and reasoning behind polio virus [9]. There are regions like Balochistan and Sindh where the articulacy rate is even below 20\% [10]. This articulacy rate is not significant in terms of parents and family being heedful and educated about the polio virus and immunization, but it is associated with the heedfulness and educational status of the health workers of those regions. A survey was executed in the Peshawar and Quetta terrain, which found that health workers who are more educated are more heedful about the polio program and committed towards the eradication of polio from Pakistan [11]. There are three high polio transmission zones (HPTZ) have been recognized in Pakistan so that the preventive and remedial actions can be planned in these areas. These recognized places are Khyber Pakhtunkhwa (KPK) area and metropolitan city Karachi. There are total 33 districts which are recognized as "highly endangered districts" [12].

\section{Immunization}

Immunization is considered as a key to eradicate polio. There are two ways of immunization to eradicate polio from children; one IPV (Inactivated Polio Vaccine) also known as Salk's vaccine and the other is OPV (Oral Polio Vaccine) also known as Sabin's vaccine [13]. Sabin's vaccine is more favorable than Salk's vaccine which has made the polio virus inactivated. Three viral serotypes containing, called trivalent polio oral vaccine is used in Pakistan [14]. The most opted option for RIAs (Routine Immunization Activities) and SIAs (Supplementary Immunization Activities) is OPV [15].

\section{GPEI plan for eradication}

There are two pillars for Global Polio Eradication Initiative (GPEI); SIAs and RIAs [16]. Surveillance (AFP + environmental surveillance) is also a pillar to detect polio cases and fourth pillar is to analyze all these activities [17]. The core pillar of eradication success is RIA [18].

\section{Role of EPI in Pakistan}

Immunization is the key to polio eradication and this service is largely provided by EPI (Expanded Program on Immunization) in Pakistan. There are 6000 centers through which immunization is provided and about 100,000 LHVs (lady health visitors) are supplemented through RIAs and SIAs. Hundreds of thousands of people paralyzed and killed by poliomyelitis every year, before the commencement of the Global Polio Eradication Initiative (GPEI) in 1988 [19].

\section{Mistrust for vaccine in Pakistan}

In Pakistan, the basic articulacy rate is about $60 \%$ higher in metropolitan areas than suburban areas where the $2 / 3$ of the population live [20]. The aspects which confer the mistrust for vaccine in Pakistan are socioeconomic, illiteracy, religious and cultural aspects [21]. A significant obstruct to the campaign is parental disallowance. They don't know about the effectiveness of immunization and think that vaccines can sterilize or harm the children. Their misconception is that the vaccines contain products derived from pig or monkey which are restricted in Islam [22].

\section{Progress towards polio eradication}

The knowledge and attitudes toward the polio vaccination are changing is attested with latest cross sectional studies proposing that the most of the public of Punjab support the program of immunization, although some hindrance be left on religious grounds [23].This diversity with findings from a cross sectional study of citizens of both highly affected areas Peshawar and Quetta where the surveillance issue, vaccine-induced infertility scare and faulty religious beliefs were recognized as major obstacles towards approval [24].

Researchers and healthcare workers are perpetually undertaking to absorb the aspects of religious and cultural susceptibility in providing of services and transmission of interventions in a trial to make these services and interventions more standard [25]. In 2015, Pakistani military in FATA made gains of continental shelf, provided more approach to vaccinator teams in areas where they were restricted [26]. In February 2015, the provincial government of KPK also started a program "Alliance for Health" to develop community engagement achievements and improve security for vaccination teams in FATA [27]. In 2015, over $80 \%$ of new reported polio cases [28] reduced as compared to 2014 [29].

\section{Why the efficacy of vaccines low?}

a) However, the wild polio virus strains exclusively eliminated by OPV (a global eradication program for polio), but this strategy did not reach to its goal of total eradication due to stopped initial success.

b) In some areas of military unrest, the lack of security for health workers and the rejection of the vaccine challenged the coverage of effective vaccine. 
c) The transmission of polio virus in some populations did not stop because of very low efficacy displayed by trivalent OPV.

d) The maintenance of high levels of population immunity will be required for the sustained control of poliomyelitis.

e) Logistical challenges and relatively high cost of administration and distribution complicated the global use of the current IPV [30].

\section{Conclusion}

Polio is an element of economic and social concern, which alarms for developing innovative plan for best quality polio immunization. Although Pakistan is strongly committed to wipe out polio still a number of threats is facing by polio eradication campaign due to operational and managerial deficits, serious inequities in immunization coverage and poor health infrastructure across the country. Effective partnership at regional, national and global levels is needed to make Pakistan a polio free country.

\section{Reference}

1. Minor PD (2012) The polio-eradication programme and issues of the end game. J Gen Virol 93(3): 457-474.

2. Shah M, Khan M K, Shakeel S, Faiza Mahmood, Zunaira Sher, et al. (2011) Resistance of polio to its eradication in Pakistan. Virol J pp. 457.

3. Flexner S, Lewis P A (1910) Experimental epidemic poliomyelitis in monkeys. Journal of Experimental Medicine 12: 227-255.

4. Sabin AB (1954) Non cytopathogenic variants of poliomyelitis viruses and resistance to superinfection in tissue culture. Science 120(3113): 357.

5. Shaikh BT (2011) Health care system in Pakistan. In: Rout HS, editor. Health care systems: a global survey. New Delhi: New Century Publications pp. 434-454.

6. (2019) World Health Organization. Polio free certification: WHO South East Asia.

7. (2016) Global Polio Eradication Initiative. Polio this week.

8. (2015) United Nations Development Programme. Human development report 2015: work for human development. New York.

9. Neurath P (2017) Taylor \& Francis Group; 2017. From Malthus to the Club of Rome and Back. Problems of Limits to Growth, Population Control and Migrations. USA.

10. Roger Moore, Mark Burdman (1997) Prince Philip's Malthusians launch new age killer cults.

11. Horowitz L (1997) Emerging Viruses: AIDS and Ebola: Nature, Accident, Or Intentional? New York, USA.
12. Roberts L (2012) Fighting polio in Pakistan. Science 337(6094): $517-$ 521.

13. Bhutta ZA, Orenstein WA (2013) Scientific declaration on polio eradication. Vaccine 31(27): 2850-2851.

14. Shah M, Khan M K, Shakeel S, Faiza Mahmood, Zunaira Sher, et al. (2011) Resistance of polio to its eradication in Pakistan. Virol 8: 457.

15. Mateen F J, Shinohara R T, Sutter R W (2013) Oral and inactivated poliovirus vaccines in the newborn: a review. Vaccine 31(21): 25172524.

16. Bhatnagar N, Grover M, Sinha S, Kaur R (2013) Poliomyelitis eradication: rhetoric or reality. Asian Pacific Journal of Tropical Disease 3(3): 240241.

17. Aylward RB, Maher C (2006) Interrupting poliovirus transmission - new solutions to an old problem. Biologicals 34(2): 133-139.

18. Khan T, Qazi J (2013) Hurdles to the global antipolio campaign in Pakistan: an outline of the current status and future prospects to achieve a polio free world. J of Epidemiol Community Health 67(8): 696-702.

19. Bhutta ZA (2011) The last mile in global poliomyelitis eradication. Lancet 378(9791): 549-552.

20. Owais A, Khowaja AR, Ali SA, Zaidi AK (2013) Pakistan's expanded programme on immunization: An overview in the context of polio eradication and strategies for improving coverage. Vaccine 31(33): 3313-3319.

21. Mushtaq A, Mehmood S, Rehman MAU, Younas A, Rehman MSU, et al. (2015) Polio in Pakistan: Social constraints and travel implications. Travel Med Infect Dis 13(5): 360-366.

22. Khan TM, Sahibzada MUK (2016) Challenges to health workers and their opinions about parents' refusal of oral polio vaccination in the Khyber PakhtoonKhawa (KPK) province, Pakistan. Vaccine 34(18): 2074-2081.

23. Iqbal MS, Iqbal MW, Iqbal MZ, Bahari MB (2015) Knowledge, Attitude and Perception of Polio (Poliomyelitis) among General Public in Pakistan. Value Health 18(7): A591.

24. Khan MU, Ahmad A, Aqeel T, Salman S, Ibrahim Q et al. (2015) Knowledge, attitudes and perceptions towards polio immunization among residents of two highly affected regions of Pakistan. BMC Public Health 15(1): 1100

25. Sirois ML, Darby M, Tolle S (2013) Understanding Muslim patients: cross-cultural dental hygiene care. Int J Dent Hyg 11(2):105-114.

26. Dawn (2015) Imran launches SehatKalttehad for KP, Fata.

27. Feldbaum H, Lee K, Michaud J (2010) Global health and foreign policy. Epidemiol Rev 32(1): 82-92.

28. Global Polio Eradication Initiative. Global Polio Eradication Initiative > Data and monitoring $>$ Polio this week $>$ Wild poliovirus list.

29. Global Polio Eradication Initiative. Wild Poliovirus List 2010-2015.

30. Korotkova EA, Park R, Cherkasova EA, Galina Y Lipskaya, Konstantin M Chumakov, et al. (2003) Retrospective analysis of a local cessation of vaccination against poliomyelitis: a possible scenario for the future. J Virol 77(23): 12460-12465 